Research article

\title{
A SINGLE DOSE VACCINATION WITH AN ELASTASE-DEPENDENT H1N1 LIVE ATTENUATED SWINE INFLUENZA VIRUS PROTECTS PIGS FROM CHALLENGE WITH 2009 PANDEMIC H1N1 VIRUS
}

\author{
MAŠIĆ Aleksandar ${ }^{1,4^{*}}$, WOLDEAB Niziti ${ }^{1}$, EMBURY-HYATT Carissa ${ }^{1}$, ZHOU Yan ${ }^{2}$, \\ BABIUK Shawn ${ }^{1,3}$

\begin{abstract}
${ }^{1}$ National Centre for Foreign Animal Disease, Canadian Food Inspection Agency, Winnipeg MB, Canada; ${ }^{2}$ Vaccine \& Infectious Disease Organization, University of Saskatchewan, Saskatoon, SK, Canada; ${ }^{3}$ Department of Immunology, University of Manitoba, Winnipeg MB, Canada; ${ }^{4}$ Bioniche Life Sciences Inc, 231 Dundas Street East Belleville, ON, Canada
\end{abstract}

(Received 29 December 2013; Accepted 15 February 2014)

\begin{abstract}
The 2009 outbreak of H1N1 influenza A viruses in humans underscored the importance of pigs in influenza A virus evolution and the emergence of novel viruses with pandemic potential. In addition, influenza $A$ virus infections continued to cause production losses in the agricultural industry resulting in a significant drop of profit. The primary method to control influenza A virus infections in pigs is through vaccination. Previously we demonstrated that two doses of an elastase-dependent live attenuated swine influenza virus administered by either the intratracheal or intranasal route can provide a high degree of protection in pigs against challenge with both homologous and different heterologous swine influenza viruses. Here we report the protection efficacy of a single dose elastase-dependent live attenuated swine influenza virus administered by the intranasal route against challenge with homologous subtypic H1N1 2009 pandemic swine-like influenza virus. Protection was observed in the absence of neutralizing antibodies specific for H1N1 2009 in sera.
\end{abstract}

Key words: H1N1; swine influenza; pandemic influenza; vaccine

\section{INTRODUCTION}

Swine influenza virus (SIV) infections are a common cause of bronchointerstitial pneumonia and respiratory disease in pigs [1]. Although the mortality of SIV infected pigs is usually low, morbidity may approach $100 \%$ leading to significant economic losses in the swine industry. SIVs are classified to the genus influenza A of the family Orthomyxoviridae, containing eight segments of a single-stranded RNA genome of negative polarity [2]. Due to their segmented genome, influenza A viruses undergo infrequent antigenic shift or reassortment, leading to generation of novel influenza A viruses. Epithelial cells in the lower part of the swine respiratory tract have receptors

\footnotetext{
*Corresponding author: e-mail: aleksandar.masic@bioniche.com
} 
for both avian and mammalian influenza viruses [3], thus pigs could potentially serve as "mixing vessels" for the generation of new reassortant strains with pandemic capacity. This has been documented for the emerged H1N1 2009 influenza A virus that was result of subsequent reassortment of swine influenza viruses in 2009 [4]. This H1N1 2009 virus contains six genes of the North American swine triple reassortant lineage with the $\mathrm{M}$ and NA acquired from the Eurasian swine lineage H1N1. In addition, H1N1 2009 viruses are characterized by increased human transmission and high pathogenicity in young adults constituting a significant public health concern $[4,5]$. The emergence of the H1N1 2009 influenza A virus demonstrated that the flow of influenza virus genes between swine and humans is bidirectional [4]. Consequently, effective control and prevention of SIV infections are required for both human and animal health.

The most common method for control of swine influenza virus infections in swine farms is through vaccination. Currently used vaccines against swine influenza are inactivated whole virus or split virus preparations for intramuscular administration. These vaccines contain antigens from representatives of the H1N1, H1N2 and H3N2 subtypes in combination with an oil adjuvant. Application of these vaccines reduces the severity of disease but does not provide consistent protection from infection [6,7]. These vaccines induce little or no heterologous immunity between influenza subtypes or genetically different viruses within subtype [8]. In contrast to inactivated vaccines, live attenuated influenza vaccines (LAIV) delivered to mucosal surfaces induce immune responses at the site of natural infection and heterologous immunity [9,10]. Live attenuated influenza vaccines also have the potential to induce broad cell-mediated and humoral immune responses which could provide better protection against antigenically distinct influenza viruses. Currently, LAIV are available for human [11] and equine species [12]. Despite several reports demonstrating the potential of LAIV to control influenza in pigs $[9,13]$ there are currently no commercially available LAIV for pigs used anywhere in the world.

It was previously demonstrated that an elastase-dependent LAIV R345V derived from $\mathrm{A} / \mathrm{Sw} /$ Saskatchewan/18789/02 (H1N1) (SIV/Sk02) is attenuated, immunogenic and protective in pigs after two intratracheal (IT) or intranasal (IN) administrations $[10,13,14]$. Attenuation of this influenza virus in pigs was achieved by converting the original HA cleavage site from a trypsin-sensitive motif to an elastase-sensitive motif [15]. This virus was demonstrated to be able to protect pigs against homologous H1N1 SIV as well as to provide partial protection against heterologous H3N2 SIV infection $[10,13]$. In addition, it was demonstrated that two vaccinations administered either by the intratracheal or intranasal route induced protection against pandemic $\mathrm{A} / \mathrm{Sw} /$ Manitoba/MAFRI32/2009 H1N1 (MAFRI09) in pigs [14]. Intranasal vaccination is a more practical way of immunization and has application to mass herd vaccination since it enables the use of smaller volumes and delivery of antigens mimicking natural infection to provide stronger immune responses [16,17]. In this study, a single intranasal administration of an elastase-dependent attenuated influenza $A$ virus was evaluated for the ability to protect pigs against H1N1 2009 challenge. 


\section{MATERIALS AND METHODS}

\section{Cells, viruses and vaccine}

Madin-Darby canine kidney (MDCK) cells were cultured in minimal essential medium (MEM) supplemented with 10\% fetal bovine serum (FBS). The H1N1 mutant virus $\mathrm{SIV} / \mathrm{Sk}-\mathrm{R} 345 \mathrm{~V}$ (R345V) used in this study was generated as previously described [15]. This virus contained a modified HA cleavage site which is only sensitive to human neutrophil elastase. Wild type H1N1 2009 virus used for a challenge purposes was A/ Sw/Manitoba/MAFRI32/2009 H1N1 (MAFRI09). Propagation and titration of these viruses was described previously $[13,14]$.

\section{Experimental design and sampling}

All study procedures and animal care activities were conducted at the National Centre for Foreign Animal Disease, Canadian Food Inspection Agency (NCFAD-CFIA), Winnipeg, Canada. The entire animal work was carried out in compliance with Canadian Council on Animal Care guidelines and was approved by the Animal Care Committee at the Canadian Science Centre for Animal and Human Health.

Eleven, four week old pigs were obtained from a local high health pig farm in Manitoba (Canada) and housed at the NCFAD-CFIA. All pigs were Duroc breed and SIV serologically negative prior to the experiments. Animals were randomly selected and divided into two groups. Veterinarian and technical staff performing vaccination, challenge, daily monitoring and necropsies were blinded for experimental groups. Pigs assigned to group $1(\mathrm{n}=5)$ were vaccinated with $1 \mathrm{ml}$ MEM containing $1 \times 10^{8}$ plaque forming units (PFU) of the R345V, while pigs assigned to group 2 ( $n=6)$ served as non-vaccinated controls (Table 1.). Pigs were vaccinated by the intranasal route $(0.5 \mathrm{ml} /$ nostril) following seven days period of acclimatization. After vaccination with R345V pigs were monitored for five consecutive days for the presence of SIV characteristic clinical signs. Consistent with previous observations [15], vaccinated pigs did not show any clinical signs related to SIV infections.

Table 1. Experimental group assignment and study design. Eleven animals were randomly assigned into two groups (Group $1[\mathrm{n}=5]$ and Group $2[\mathrm{n}=6]$ ). Animals in both groups were vaccinated intranasally with either R345V or MEM (control). Two weeks following vaccination animals in both groups were challenged intranasally with 2009 H1N1 SIV and euthanized 5 days post challenge.

\begin{tabular}{|c|c|c|c|c|}
\hline Group (\#N) & Vaccination & Dose & Route & Challenge \\
\hline 1. (5) & $\mathrm{R} 345 \mathrm{~V}$ & $\begin{array}{c}1 \mathrm{ml} \\
\left(1 \times 10^{8} \mathrm{pfu} / \mathrm{ml}\right)\end{array}$ & Intranasal & $\begin{array}{c}\text { SIV/MAFRI } 2009 \\
\text { H1N1 }\end{array}$ \\
\hline 2. (6) & MEM & $1 \mathrm{ml}$ & Intranasal & $\begin{array}{c}\text { SIV/MAFRI } 2009 \\
\text { H1N1 }\end{array}$ \\
\hline Vaccination & & & challenge & euthanasia \\
\hline$\underset{\text { Day } 0}{\nabla}$ & & & $\underset{D a y 15}{\|}$ & $\begin{array}{c}\boldsymbol{\nabla} \\
\text { Day } 20\end{array}$ \\
\hline
\end{tabular}


Fifteen days after the vaccination, pigs in both groups were challenged intranasally with $10^{6}$ tissue culture infectious doses $\left(\right.$ TCID $_{50}$ ) of MAFRI09 in a $1 \mathrm{ml}$ volume of MEM. Following the H1N1 2009 challenge, all pigs were monitored for five consecutive days for the presence of fever and SIV characteristic clinical signs. At the end of the observation period (day 20) all pigs in both experimental groups were humanely euthanized with a lethal dose of pentobarbital sodium (Euthanyl® 250mg/ml; BimedaMTC Animal Health Inc, Canada) and subjected to necropsy. At necropsy, lungs were removed, evaluated and scored for the presence of SIV characteristic gross lesions. The percentage of the areas affected with pneumonia was estimated visually for each lung lobe. The total percentage for the entire lung was calculated based on weight proportions of each lung lobe to the total lung volume [18].

Sera were collected from the pigs prior and after vaccination (days -7, 0, 15) and at necropsy (day 20). Nasal swabs were taken prior to challenge and every day for five consecutive days post challenge. At necropsy, tissue samples from right apical, cardiac and diaphragmatic lobes were collected for histopathology evaluation and virus isolation.

\section{Evaluation of viral loads}

Lung tissue and nasal swab samples were processed as previously described [15]. Viral RNA was isolated from swabs and 10\% lung homogenates using an RNeasy Mini Kit (Qiagen; Cat \#74106) according to the manufacturer's instructions. Viral loads in nasal swabs and lung homogenates were determined by a real-time (RT-PCR) assay specific for the influenza A virus matrix (M1) gene [19] with primers and probes that were modified to enhance detection of pandemic swine-like H1N1 2009 [20-22]. In addition, the levels of infectious virus from lung samples were determined by virus isolation on MDCK cells as previously described [13,15].

\section{Evaluation of antibody responses}

Influenza A virus specific antibodies in serum were detected using a competitive ELISA (cELISA) specific for the influenza A virus nucleoprotein (NP) [23] as well as IDEXX HerdChek SIV Test Kit (IDEXX Laboratories, Westbrook ME). A virus neutralization test (VNT) was conducted in 96-well microtiter plates (Corning Incorporated, NY), according to methods described in "WHO Manual on Animal Influenza Surveillance and Diagnosis" [24]. Sera were heat treated, serially diluted, each serial dilution mixed with equal volumes of $100 \mathrm{TCID}_{50}$ of MAFRI09 and then incubated at $37^{\circ} \mathrm{C}$ for 30 min. The mixtures were then transferred onto a confluent monolayer of MDCK cells prepared on 96-well flat-bottom plates (Corning Incorporated, NY) and incubated at $37^{\circ} \mathrm{C}$ and $5 \% \mathrm{CO}_{2}$ for $96 \mathrm{~h}$. After 4 days incubation, infected cells were fixed with $10 \%$ formalin and immunostaining was performed to visualize influenza infected cells. The neutralization titer was expressed at the highest dilution of serum that prevented viral cytopathic effect (CPE). 


\section{Histopathology and Immunohistochemistry (IHC)}

Tissue samples of right apical, cardiac and diaphragmatic lung lobes were collected from all 11 animals at 5 days post challenge. Additional samples of lung were collected from other areas of lungs if additional lesions were observed during post mortem examination. Tissue samples were fixed in 10\% neutral phosphate buffered formalin, routinely processed and stained with hematoxylin and eosin (H\&E) for histopathologic examination. Visualisation of influenza specific antigens in lung tissues by immunohistochemistry (IHC) was performed as previously described [14]. Positive staining for Influenza A virus nucleoprotein was graded according to amount of antigen detected in the lung. Board certified pathologist examined all slides and was blinded for experimental groups.

\section{Statistics}

Statistical analysis of macroscopic, microscopic lesions, antibody and virus titers were performed using GraphPad Prism5 statistical software (GraphPad Software Inc, CA, US). Differences between medians in two groups (vaccinated vs. unvaccinated) in each assay were determined using a Mann-Whitney nonparametric t-test. For statistical comparison of virus shedding from upper respiratory tract between vaccinated and non-vaccinated challenged pigs (RT-PCR from nasal swabs) standard two-way ANOVA which compares the differences among group means with the pooled standard deviations of the groups was used. If the median or mean (ANOVA) values of at least one group differed from others with a $\mathrm{P}<0.05$ they were considered statistically significant.

\section{RESULTS}

\section{Clinical signs and gross pathology}

Fifteen days after the single intranasal immunization, pigs were challenged intranasally with H1N1 MAFRI09 and observed for 5 days. At the end of observation period (day 20) all 11 pigs were euthanized and necropsies were performed. During the five-day observation period no apparent clinical signs with respect to respiratory distress and nasal discharge were observed in both experimental groups (groups 1 and 2). Clinical disease following A/Sw/Manitoba/MAFRI32/2009 H1N1 challenge was very similar to that observed following A/Mexico/InDRE4487/2009 H1N1 challenge [25].

All unvaccinated control pigs following H1N1 2009 challenge developed lesions typical for SIV (Fig 1. B and C) characterized by sharply demarcated, purple coloured consolidated areas most prevalent in the cardiac and apical lobes (median score of 9.0). In contrast, 3 out of 5 pigs vaccinated with R345V by intranasal administration and challenged with MAFRI09, had detectable minimal gross lesions corresponding to SIV infections (median score of 1.5). Although lung lesions were seen in pigs vaccinated and challenged with H1N1 2009 (Fig 1. A), the severity and distribution of lesions was significantly reduced compared to unvaccinated controls $(\mathrm{P}=0.043)$ (Fig. 1D). These data were consistent with our previous observation $[10,13,14]$. 


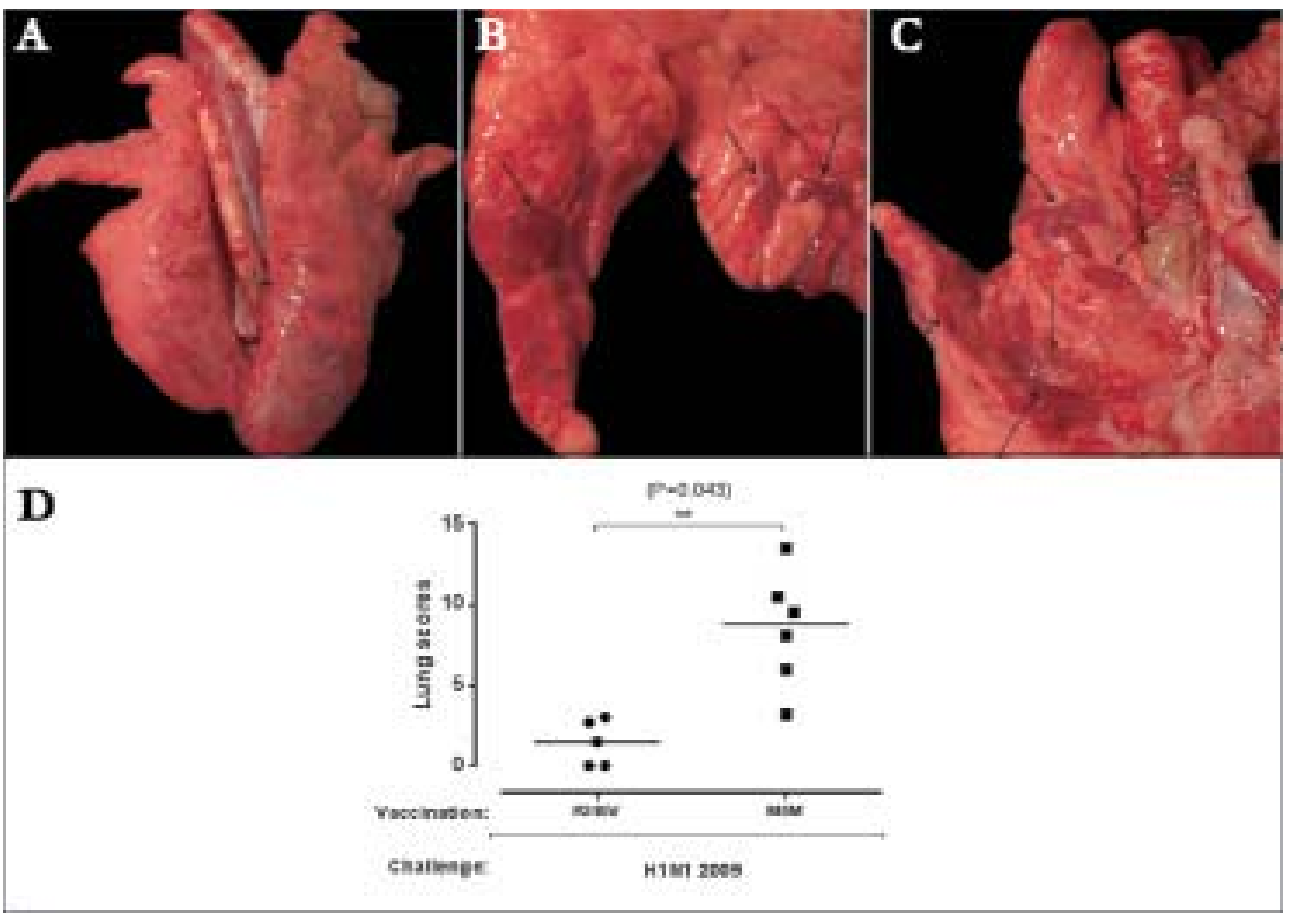

Figure 1. Necropsy (A) Representative pig lungs from vaccinated (R345V) and H1N1 2009 challenged group; Apical and cardiac lung lobes [dorsal (B) and ventral (C) view] from representative of unvaccinated and H1N1 2009 challenged group; Gross lung pathology scores (D) Lungs from vaccinated and unvaccinated pigs were assessed for gross pathology 5 days following H1N1 2009 challenge. Differences between vaccinated (R345V) pigs compared to control (MEM) pigs were determined using a Mann-Whitney nonparametric t-test $\mathrm{P}<0.05$. The bar represents the median.

\section{Histopathology and Immunohistochemistry}

Lung sections from apical, cardiac and diaphragmatic lobes were evaluated for microscopic lesions at five days post challenge. In general, for both control and vaccinated groups, the most prominent lesions were observed in the cardiac lobes. In the non-vaccinated control pigs, all animals showed moderate to severe lesions that were multifocal and lobular. Lesions were characterized by necrotizing bronchiolitis with necrotic debris and neutrophils in bronchiolar lumina. There were perivascular, peribronchiolar and interstitial infiltrates of lymphocytes and plasma cells with atelectasis of alveoli adjacent to the bronchiolar lesions (Fig. 2A). In some areas alveoli contained exudates composed of edema fluid and neutrophils. Multifocally, alveolar septa were hypercellular. In 4 out of 5 vaccinated animals there were occasional mild peribronchiolar and/or interstitial infiltrates of lymphocytes and plasma cells (Fig. 2C). In one vaccinated animal there were 2 small focal areas of bronchiolitis and atelectasis in the section from the cardiac lobe (Fig. 2E).

Using immunohistochemistry, sections were evaluated for the presence of influenza A virus specific antigen. In all of non-vaccinated control pigs, there was extensive positive immunostaining within bronchiolar epithelial cells as well as within cells of the alveolar 
walls which were identified by morphology to be primarily macrophages with occasional pneumocytes (Fig. 2B). Within the vaccinated group, viral antigen could not be detected in 4 out of 5 animals (Fig. 2D). In one vaccinated animal there were 2 small areas of positive immunostaining in the lung section from the cardiac lobe which included primarily
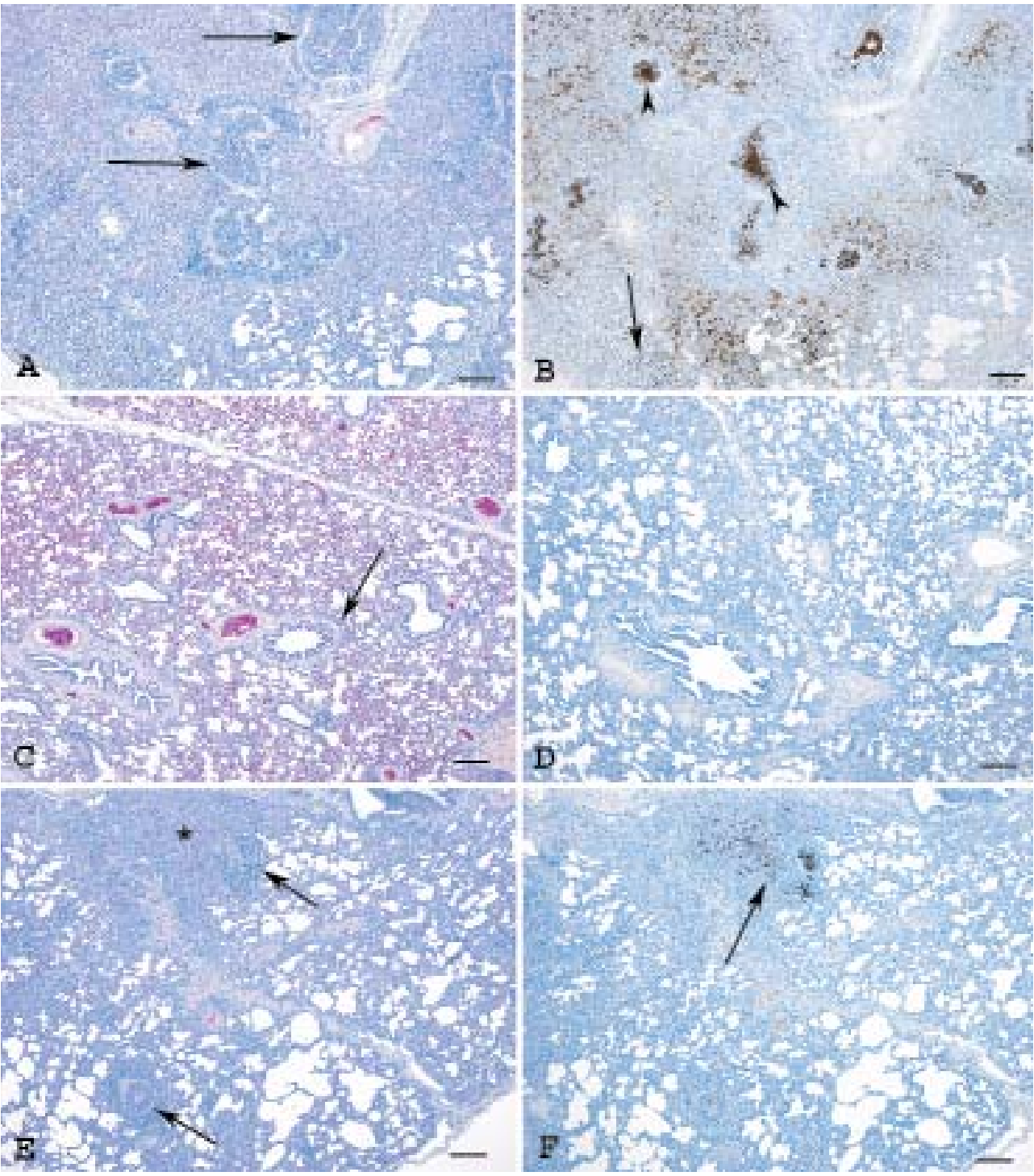

Figure 2. Histopathology and immunohistochemistry findings at 5 days post infection. Lung section from a non-vaccinated (challenge) control pig: (A) (H\&E) with extensive atelectasis, alveolitis and bronchiolitis (arrows). (B) (IHC) extensive positive immunostaining within bronchioles (arrowhead), neutrophilic exudates $(*)$ and alveolar cells (arrow). Lung section representative of 4 out of 5 vaccinated pigs following challenge: (C) (H\&E) with mild peribronchiolar lymphoplasmacytic infiltrate (arrow) and (D) (IHC) viral antigen could not be detected. Lung section from one vaccinated pig: (E) (H\&E) with occasional bronchiolitis (arrows) and (F) (IHC) a focal area of positive immunostaining corresponds to the presence of a lesion (arrow). Bar $=200 \mu \mathrm{m}$ in all figures. 
bronchiolar epithelium and a few cells within alveolar walls with the morphological appearance of macrophages (Fig. 2F). Both nuclear and cytoplasmic immunostaining pattern was observed within the bronchiolar epithelial cells in control animals as well as in the one vaccinated animal where staining was observed. Furthermore, cells within alveolar walls showed both cytoplasmic and nuclear immunostaining. Although cells in alveolar walls could not definitely be identified by histopathology many are large cells with irregular borders, abundant cytoplasm and large nuclei and are located within the interstitium and possibly within capillaries which suggests they could be interstitial macrophages or pulmonary intravascular macrophages.

\section{Vaccination with R345V reduces viral loads in the lung and nasal swabs}

To evaluate the efficacy of $\mathrm{R} 345 \mathrm{~V}$ single dose vaccine administered by the intranasal route against H1N1 2009 MAFRI09 we isolated virus from apical and cardiac lobes and compared the viral loads between vaccinated and control pigs. Consistent with previous observations at necropsy, histopathology and IHC, a significant reduction of virus load by two to three orders of magnitude was observed in vaccinated pigs compared to control pigs in both the apical and cardiac lung lobes (Fig. 3). Virus was recovered from cardiac lobes of two vaccinated and challenged animals with the titers significantly lower than in control challenged group $(\mathrm{P}=0.027$ and $\mathrm{P}=0.047)$. RT-PCR analysis of apical and cardiac lung lobe samples confirmed the virus isolation results with a significant $(\mathrm{P}=0.0195$ and $\mathrm{P}=0.021)$ reduction of viral $\mathrm{RNA}$ in vaccinated pigs compared to control pigs (Fig. 4).
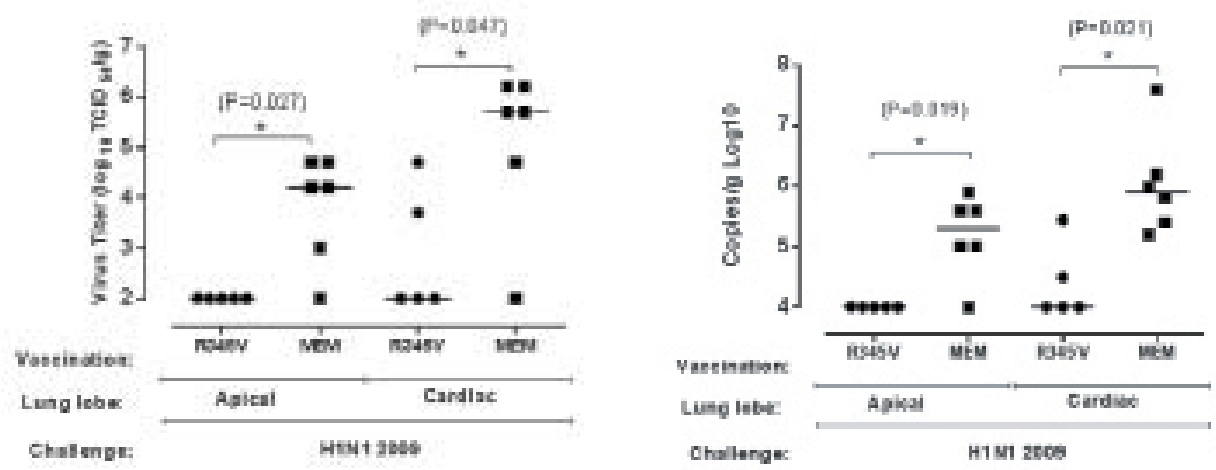

Figure 3. Lung virus titers. Lung tissues from Figure 4. Influenza viral genome copies in the apical and cardiac lobes were homogenized lungs. Lung tissues from the apical and cardiac and virus titers were determined on MDCK lobes were homogenized and viral genome cells. Differences between vaccinated (R345V) copies were determined by real time RTpigs compared to control (MEM) pigs were de- PCR assay. Differences between vaccinated termined using a Mann-Whitney nonparametric (R345V) pigs compared to control (MEM) $\mathrm{t}$-test $\mathrm{P}<0.05$. The bar represents the median. pigs were determined using a Mann-Whitney The limit of detection for the virus isolation nonparametric t-test $\mathrm{P}<0.05$. The bar was $2 \log _{10} / g$ and is a default value for samples represents the median. The bar represents the below the limit of detection. median. The limit of detection for the real time RT-PCR assay for lung homogenates was 4 $\log _{10} / \mathrm{g}$ and is a default value for samples below the limit of detection. 
RT-PCR was used to evaluate viral shedding in nasal swabs collected for five consecutive days following challenge. Prior to challenge nasal swabs were collected from all pigs and were negative for influenza virus RNA. Viral RNA was detected by real-time RT-PCR at days two and three post challenge in 2 (day 2) and 1 (day 3) out of 5 vaccinated pigs (Fig. 5). In contrast, non-vaccinated control pigs following H1N1 2009 challenge had detectable viral RNA during the all five days post challenge (Fig. 5). Vaccination with $\mathrm{R} 345 \mathrm{~V}$ significantly reduced $(\mathrm{P}=0.0067)$ the levels of potential virus shedding from upper respiratory tract determined by the presence of viral RNA detected by RT-PCR in nasal swabs.

A

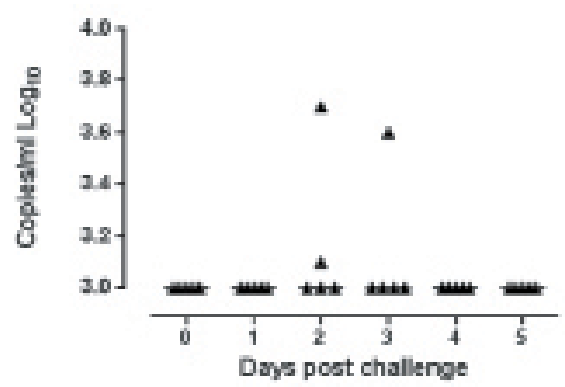

B

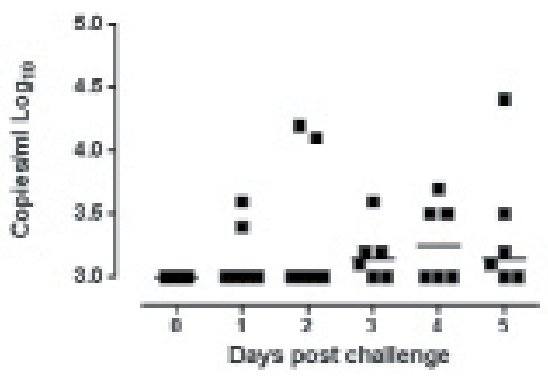

Figure 5. Influenza viral genome copies in nasal swabs. Nasal swabs were collected prior to and daily following H1N1 2009 challenge (A) in vaccinated and (B) unvaccinated control pigs; viral genome copies were determined by real time RT-PCR assay. The bar represents the median. The limit of detection for the real time RT-PCR assay for swabs was $3 \log _{10} / \mathrm{ml}$ and is a default value for samples below the limit of detection.

\section{Serology following single vaccination of R345V}

Prior to vaccination all pigs were negative for influenza specific antibodies as determined by IDEXX, cELISA and VNT against H1N1 2009. Fifteen days following intranasal vaccination with the R345V, all 5 pigs generated anti-influenza virus antibodies assessed using the IDEXX and cELISA (data not shown) but had no any detectable neutralizing antibodies against H1N1 2009 (Fig. 6). Unvaccinated control pigs did not have and influenza specific antibodies prior to challenge. Five days post challenge, significant levels of neutralizing antibodies to H1N1 2009 were detected in sera of all five vaccinated pigs whereas unvaccinated control pigs did not develop significant neutralizing antibodies (Fig. 6). 


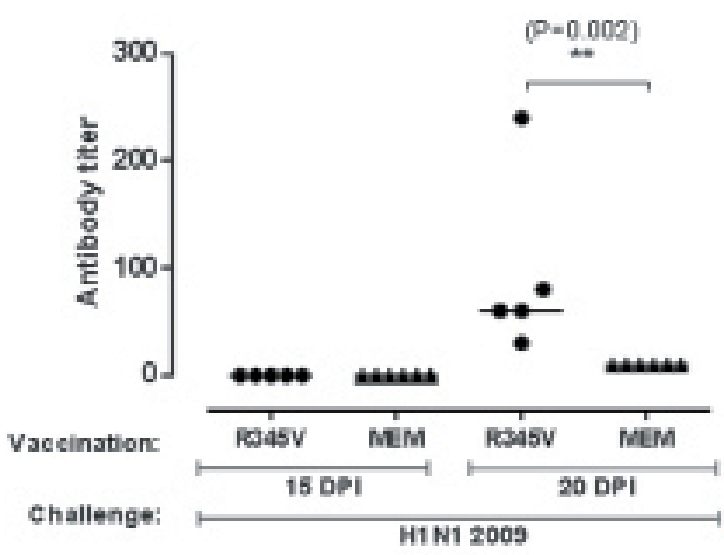

Figure 6. H1N1 2009 neutralizing antibody titers. Prior to (15 DPI) and 5 days following H1N1 2009 challenge (20 DPI) sera from vaccinated (R345V) and control pigs (MEM) were evaluated for H1N1 2009 neutralizing antibodies. Differences between vaccinated (R345V) pigs compared to control (MEM) pigs following $\mathrm{H} 1 \mathrm{~N} 1$ challenge were determined using a MannWhitney nonparametric t-test $\mathrm{P}<0.05$. The bar represents the median.

\section{DISCUSSION}

The main advantage of LAIV compared to their inactivated counterparts is the induction of both cell-mediated (CMI) and antibody mediated immunity at the site of infection that resemble the natural infection [16]. The activation of CMI and strong mucosal antibody response are crucial in developing long-lived cross-protective immunity against influenza A virus infections. However, the major regulatory issue in the use of live attenuated viruses as vaccines is the possibility of its reversion of pathogenicity and reassortment with current wild type viruses. This gene exchange could possibly lead to the generation of new circulating viruses with the potential in emerging to pandemic viruses. In order to mitigate this issue, the virus attenuated to generate the vaccine should be comprised of viral genes of low virulence.

With the elastase-dependent LAIV vaccine model the general fear that the HA gene of LAIV would revert and reassort into circulating viruses was prevented by genetic modification of HA within cleavage site $[15,26]$. Using the well-established molecular techniques, influenza viruses with modified cleavage site can be easily engineered and rapidly propagated in vitro in the presence of the appropriate proteases $[15,26,27]$. The mutation within HA cleavage site serve as an attenuation phenotype which could be inherited by the wild type virus in the case of reassortant leading to the attenuation of the wild type virus. In addition, the elastase enzyme is present in limited quantities in sites where the virus replicates in vivo, thus virus replication is also restricted. This limited 
replication is important as it decreases the probability of any mutation or reassortment with any wild type virus making this LAIV a safer candidate.

Previously we demonstrated that R345V an elastase-dependent non-homologous H1N1 vaccine administered twice either by the intranasal or intratreacheal routes was able to reduce lung pathology, virus replication and virus shedding following H1N1 2009 challenge [14]. In the current study, it was investigated whether the R345V elastasedependent SIV is capable of providing protection against H1N1 2009 SIV following a single intranasal vaccination. The result of this study demonstrate that despite restricted replication and short antigen exposure, R345V SIV cleavage mutant showed significant immunogenicity and the ability to protect against heterologous H1N1 SIV challenge following a single intranasal administration. The R345V elastase-dependent nonhomologous H1N1 vaccine administered once by the intranasal route was able to reduce lung pathology, virus replication and virus shedding following H1N1 2009 challenge. The gross pathology along with histopathology, IHC results, virus isolation and realtime RT-PCR results from upper and lower respiratory tract indicated that the single dose vaccination with $\mathrm{R} 345 \mathrm{~V}$ significantly reduces viral replication following H1N1 2009 challenge and is close to generating sterile immunity. In addition, the elastaseattenuated vaccine was able to reduce viral shedding in nasal swabs of vaccinated pigs which is critical to reduce influenza transmission and evolution in the field.

Cross-neutralizing antibodies to H1N1 2009 were detected only following challenge with H1N1 2009. This observation was not unexpected since it was previously demonstrated that following a single vaccination with $\mathrm{R} 345 \mathrm{~V}$ administered by the intratracheal or intranasal route rarely induced detectable cross-neutralizing antibodies. Although neutralizing antibodies are important in preventing influenza virus infection, the results demonstrate remarkable protection in R345V vaccinated pigs to H1N1 2009 challenge in the absence of specific neutralizing antibodies against H1N1 2009. Protection in the absence of cross-neutralizing antibodies indicates that factors such as non-neutralizing antibodies may be important in the clearance of influenza virus by macrophages. Furthermore, cell mediated immunity against influenza is likely a key component in controlling influenza virus replication and providing cross-protection. Previously we demonstrated that R345V elastase-dependent SIV elicited significant influenza specific cell mediated immunity, detected by the induction of IFN- $\gamma$ secreting cells from cells in the draining lymph nodes following primary and secondary immunizations $[10,13]$. Live attenuated influenza vaccines that can elicit broad protection against nonhomologous influenza viruses of the same type, combined with biosecurity and surveillance, would enhance pandemic preparedness against newly emerging influenza. The development of several live attenuated influenza viruses covering the HA subtypes that have the pandemic potential, would enhance influenza pandemic preparedness. Since the vaccine can be manufactured prior to the emergence of a new influenza virus and then tested for efficacy immediately without having to develop and produce a new vaccine. The demonstration of vaccine efficacy following single intranasal administration is a major step to application of this vaccine in the field. Further field trials of this vaccine are necessary to evaluate the protective efficacy of this vaccine in field conditions. 


\section{ACKNOWLEDGEMENTS}

We thank the Animal Care Unit at NCFAD for providing animal care. Technical support was provided by the Reagent Development Unit. Histopathology and immunohistochemistry processing was provided by Estella Moffat, and Brad Collignon in the Pathology unit. We appreciate Soren Alexandersen for critically reading the manuscript. Yan Zhou is partly supported by Natural and Engineering Research Council of Canada and Ministry of Agriculture of Saskatchewan. Shawn Babiuk is partly supported by the Canadian Institutes of Health Research.

\section{REFERENCES}

1. Easterday, B.C., Van Reeth, K., 1999. Swine influenza. In: Straw, B.E., D'Allaire, S., Mengeling, W.L., Taylor, D.J. (Eds.), Diseasesof Swine. Iowa State University Press, Ames, pp. 277-290.

2. Palese P, Shaw ML. Orthomyxoviridae: The Viruses and Their Replication. In: Knipe DM, Howley PM, editors. Fields Virology. 5th Edition. Vol. 2. Philadelphia: Lippincott Williams \& Wilkins; 2007. 1647-1689

3. Ito T, Couceiro JN, Kelm S, Baum LG, Krauss S, Castrucci MR, Donatelli I, Kida H, Paulson JC, Webster RG et al: Molecular basis for the generation in pigs of influenza A viruses with pandemic potential. J Virol 1998, 72(9):7367-7373.

4. Garten RJ, Davis CT, Russell CA, Shu B, Lindstrom S, Balish A, Sessions WM, Xu X, Skepner E, Deyde V et al: Antigenic and genetic characteristics of swine-origin 2009 A(H1N1) influenza viruses circulating in humans. Science 2009, 325(5937):197-201.

5. Smith GJ, Vijaykrishna D, Bahl J, Lycett SJ, Worobey M, Pybus OG, Ma SK, Cheung CL, Raghwani J, Bhatt S et al: Origins and evolutionary genomics of the 2009 swine-origin H1N1 influenza A epidemic. Nature 2009, 459(7250):1122-1125.

6. Macklin MD, McCabe D, McGregor MW, Neumann V, Meyer T, Callan R, Hinshaw VS, Swain WF: Immunization of pigs with a particle-mediated DNA vaccine to influenza A virus protects against challenge with homologous virus. J Virol 1998, 72(2):1491-1496.

7. Brown GB, McMillen, J.K: MaxiVac-Flu: evaluation of the safety and efficacy of a swine influenza vaccine. In: ProcAm AssocSwine Pract 25th Annual Meeting. 1994: 37-39.

8. Tamura S, Tanimoto T, Kurata T: Mechanisms of broad cross-protection provided by influenza virus infection and their application to vaccines. Jpn J Infect Dis 2005, 58(4):195207.

9. Vincent AL, Ma W, Lager KM, Janke BH, Webby RJ, Garcia-Sastre A, Richt JA: Efficacy of intranasal administration of a truncated NS1 modified live influenza virus vaccine in swine. Vaccine 2007, 25(47):7999-8009.

10. Masic A, Lu X, Li J, Mutwiri GK, Babiuk LA, Brown EG, Zhou Y: Immunogenicity and protective efficacy of an elastase-dependent live attenuated swine influenza virus vaccine administered intranasally in pigs. Vaccine 2010, 28(43):7098-7108.

11. Belshe RB: Current status of live attenuated influenza virus vaccine in the US. Virus Res 2004, 103(1-2):177-185.

12. Townsend HG, Penner SJ, Watts TC, Cook A, Bogdan J, Haines DM, Griffin S, Chambers 
T, Holland RE, Whitaker-Dowling P et al: Efficacy of a cold-adapted, intranasal, equine influenza vaccine: challenge trials. Equine Vet J 2001, 33(7):637-643.

13. Masic A, Booth JS, Mutwiri GK, Babiuk LA, Zhou Y: Elastase-dependent live attenuated swine influenza $A$ viruses are immunogenic and confer protection against swine influenza A virus infection in pigs. J Virol 2009, 83(19):10198-10210.

14. Babiuk S, Masic A, Graham J, Neufeld J, van der Loop M, Copps J, Berhane Y, Pasick J, Potter A, Babiuk LA et al: An elastase-dependent attenuated heterologous swine influenza virus protects against pandemic H1N1 2009 influenza challenge in swine. Vaccine 2011, 29(17):3118-3123.

15. Masic A, Babiuk LA, Zhou Y: Reverse genetics-generated elastase-dependent swine influenza viruses are attenuated in pigs. J Gen Virol 2009, 90(Pt 2):375-385.

16. Cox RJ, Brokstad KA, Ogra P: Influenza virus: immunity and vaccination strategies. Comparison of the immune response to inactivated and live, attenuated influenza vaccines. Scand J Immunol 2004, 59(1):1-15.

17. O’Hagan DT, Rappuoli R: Novel approaches to vaccine delivery. Pharm Res 2004, 21(9):1519-1530.

18. Richt JA, Lager KM, Janke BH, Woods RD, Webster RG, Webby RJ: Pathogenic and antigenic properties of phylogenetically distinct reassortant $\mathrm{H} 3 \mathrm{~N} 2$ swine influenza viruses cocirculating in the United States. J Clin Microbiol 2003, 41(7):3198-3205.

19. Vincent AL, Lager KM, Ma W, Lekcharoensuk P, Gramer MR, Loiacono C, Richt JA: Evaluation of hemagglutinin subtype 1 swine influenza viruses from the United States. Vet Microbiol 2006, 118(3-4):212-222.

20. Weingartl HM, Albrecht RA, Lager KM, Babiuk S, Marszal P, Neufeld J, Embury-Hyatt C, Lekcharoensuk P, Tumpey TM, Garcia-Sastre A et al: Experimental infection of pigs with the human 1918 pandemic influenza virus. J Virol 2009, 83(9):4287-4296.

21. Babiuk S, Albrecht R, Berhane Y, Marszal P, Richt JA, Garcia-Sastre A, Pasick J, Weingartl H: 1918 and 2009 H1N1 influenza viruses are not pathogenic in birds. J Gen Virol 2010, 91(Pt 2):339-342.

22. Howden KJ, Brockhoff EJ, Caya FD, McLeod LJ, Lavoie M, Ing JD, Bystrom JM, Alexandersen S, Pasick JM, Berhane Y et al: An investigation into human pandemic influenza virus (H1N1) 2009 on an Alberta swine farm. Can Vet J 2009, 50(11):1153-1161.

23. Zhou EM, Chan M, Heckert RA, Riva J, Cantin MF: Evaluation of a competitive ELISA for detection of antibodies against avian influenza virus nucleoprotein. Avian Dis 1998, 42(3):517-522.

24. OIE: Manual of Diagnostic Tests and Vaccines for Terrestrial Animals,. In., Fifth edn; 2004: Chapter 2.10.11 Swine Influenza.

25. Weingartl HM, Berhane Y, Hisanaga T, Neufeld J, Kehler H, Emburry-Hyatt C, Hooper-McGreevy K, Kasloff S, Dalman B, Bystrom J et al: Genetic and pathobiologic characterization of pandemic H1N1 2009 influenza viruses from a naturally infected swine herd. J Virol 2010, 84(5):2245-2256.

26. Stech J, Garn H, Wegmann M, Wagner R, Klenk HD: A new approach to an influenza live vaccine: modification of the cleavage site of hemagglutinin. Nat Med 2005, 11(6):683-689.

27. Gabriel G, Garn H, Wegmann M, Renz H, Herwig A, Klenk HD, Stech J: The potential of a protease activation mutant of a highly pathogenic avian influenza virus for a pandemic live vaccine. Vaccine 2008, 26(7):956-965. 


\title{
VAKCINACIJA SA JEDNOM DOZOM ELASTAZA-ZAVISNOG ŽIVOG ATENUIRANONG H1N1 VIRUSA INFLUENCE SVINJA OBEZBEĐUJE DOVOLJNU ZAŠTITU PROTIV 2009 PANDEMIČNOG H1N1 VIRUSA KOD SVINJA
}

\author{
MAŠIĆ Aleksandar, WOLDEAB Niziti, EMBURY-HYATT Carissa, ZHOU Yan, \\ BABIUK Shawn
}

Pandemija izazvana virusom influence A tipa H1N1 u 2009. godini, istakla je značaj svinja u evoluciji virusa influence A i pojavu novih virusa sa pandemijskim potencijalom. Takođe, infekcije virusom influence A značajno doprinose smanjenju proizvodnje u poljoprivrednoj industriji što za rezultat ima povećanje gubitaka i značajan pad profita. Primarni metod za kontrolu virusnih infekcija izazvanih virusom influence A kod svinja je putem vakcinacije. Prethodno smo demonstrirali da dve doze elastaza-zavisnog, živog atenuiranog virusa influence svinja date intratrahealno ili intranazalno mogu da obezbede visok stepen zaštite svinja od novih infekcija sa homolognim i različitim heterologim virusima influence svinja. U ovom radu smo opisali efikasnost vakcinacije jedne doze elastaza-zavisnog, živog atenuiranog virusa influence svinja, date intranazalno, protiv infekcije sa homolognim 2009 pandemičnim virusom subtipa H1N1. Zaštita protiv H1N1 2009 virusa kod vakcinisanih svinja je primećena i u odsustvu neutralizacionih antitela u serumu specifičnih za H1N1 2009 virus. 